\title{
Evaluation of High Solids Alkaline Pretreatment of Rice Straw
}

\author{
Yu-Shen Cheng • Yi Zheng • Chao Wei Yu • \\ Todd M. Dooley • Bryan M. Jenkins • \\ Jean S. VanderGheynst
}

Received: 22 December 2009 / Accepted: 29 March 2010 /

Published online: 4 May 2010

(C) The Author(s) 2010. This article is published with open access at Springerlink.com

\begin{abstract}
Fresh-harvested, air-dried rice straw was pretreated at a water content of $5 \mathrm{~g} \mathrm{H}_{2} \mathrm{O} / \mathrm{g}$ straw using sodium hydroxide $(\mathrm{NaOH})$ and compared to pretreatment at $10 \mathrm{~g} \mathrm{H}_{2} \mathrm{O} / \mathrm{g}$ straw by hydrated lime $\left(\mathrm{Ca}(\mathrm{OH})_{2}\right)$. Full factorial experiments including parallel wash-only treatments were completed with both sources of alkali. The experiments were designed to measure the effects of alkaline loading and pretreatment time on delignification and sugar yield upon enzymatic hydrolysis. Reaction temperature was held constant at $95^{\circ} \mathrm{C}$ for lime pretreatment and $55^{\circ} \mathrm{C}$ for $\mathrm{NaOH}$ pretreatment. The range of delignification was $13.1 \%$ to $27.0 \%$ for lime pretreatments and was $8.6 \%$ to $23.1 \%$ for $\mathrm{NaOH}$ pretreatments. Both alkaline loading and reaction time had significant positive effects $(p<0.001)$ on delignification under the design conditions, but only alkaline loading had a significant positive effect on enzymatic hydrolysis. Treatment at higher temperature also improved delignification; delignification with water alone ranged from $9.9 \%$ to $14.5 \%$ for pretreatment at $95^{\circ} \mathrm{C}$, but there was little effect observed at $55^{\circ} \mathrm{C}$. Post-pretreatment washing of biomass was not necessary for subsequent enzymatic hydrolysis. Maximum glucose yields were $176.3 \mathrm{mg} / \mathrm{g}$ dried biomass (48.5\% conversion efficiency of total glucose) in lime-pretreated and unwashed biomass and were $142.3 \mathrm{mg} / \mathrm{g}$ dried biomass (39.2\% conversion efficiency of total glucose) in $\mathrm{NaOH}$-pretreated and unwashed biomass.
\end{abstract}

Keywords Lime $\cdot$ Calcium hydroxide $\cdot$ Sodium hydroxide $\cdot$ Alkaline pretreatment . Biomass $\cdot$ Rice straw $\cdot$ Delignification $\cdot$ Enzymatic hydrolysis

\section{Introduction}

The Energy Independence and Security Act of 2007, also known as Renewable Fuel Standard II (RFS II), has extended the roadmap of renewable fuel production by raising the original goal from 9 billion gallons in 2008 to 36 billion gallons in 2022 [1]. The RFS II

Y.-S. Cheng $\cdot$ Y. Zheng $\cdot$ C. W. Yu • T. M. Dooley • B. M. Jenkins $\cdot$ J. S. VanderGheynst $(\bowtie)$ Department of Biological and Agricultural Engineering, University of California, Davis,

Davis, CA 95616, USA

e-mail: jsvander@ucdavis.edu 
also specifies that 21 billion of the 36 billion gallons of biofuel should come from renewable feedstocks other than corn seed. The development of lignocellulosic biomass sources as feedstocks for liquid fuel production is important for achieving these goals. Among different sources of biomass, agricultural residues have gained considerable interest because they are produced in great quantity on a regular basis. Developing approaches for efficient harvest, transportation and storage of biomass, and advanced, cost-efficient pretreatment methods are critical to the future utilization of agricultural residues for liquid fuel production.

Rice straw has the potential to serve as a relatively inexpensive feedstock for biofuel production because of its abundance and low value for other applications [2]. In 2007, worldwide rice production was 157 million hectare (651 million tons) [3] with estimated rice straw generation of 5.6 to $6.7 \mathrm{t} / \mathrm{ha}$ (628-785 million dry tons) [4, 5]. This amount of rice straw can theoretically produce 69 to 86 billion gallons of ethanol, which has $21 \%$ to $26 \%$ of the energy equivalence of the gasoline consumed worldwide in 2005 [6, 7].

Like other sources of lignocellulosic biomass, rice straw requires pretreatment to improve the efficiency of enzymatic hydrolysis. Several pretreatment methods have been developed to increase the enzymatic hydrolysis sugar yields from lignocellulosic biomass [8-11]. Alkaline pretreatment is one approach that has several potential advantages compared to other pretreatment processes including low operation cost, reduced degradation of holocellulose, and subsequent formation of inhibitors for downstream processing [8]. The main mechanisms of alkaline pretreatment are the degradation of ester bonds and cleavage of glycosidic linkages in the lignocellulosic cell wall matrix, which lead to the alteration of the structure of lignin, the reduction of the lignin-hemicellulose complex, cellulose swelling, and the partial decrystallization of cellulose [12-14].

Studies of $\mathrm{Ca}(\mathrm{OH})_{2}$ pretreatment have been done on different sources of lignocellulosic biomass, such as corn stover, switchgrass, bagasse, wheat straw, and rice hull, and have been shown to successfully increase the enzymatic hydrolysis sugar yields [15-18]. When compared to other sources of alkali, $\mathrm{Ca}(\mathrm{OH})_{2}$ is a relatively inexpensive reagent and easily handled. In 2005 , the price was $\sim \$ 70 /$ ton for hydrated lime, $\sim \$ 325 /$ ton for sodium hydroxide ( $\mathrm{NaOH}, 50 \%$ liquid), $\sim \$ 322 /$ ton for potassium hydroxide $(\mathrm{KOH}, 45 \%$ liquid), $\sim 270$ /ton for ammonia (fertilizer grade, anhydrate), and $\sim \$ 1,110 /$ ton for hydrogen peroxide $\left(50 \%\right.$, as is basis) [7]. However, $\mathrm{Ca}(\mathrm{OH})_{2}$ has very limited solubility in water: $1.6 \mathrm{~g} / \mathrm{L}$ at $20^{\circ} \mathrm{C}$ and $0.71 \mathrm{~g} / \mathrm{L}$ at $100^{\circ} \mathrm{C} \mathrm{[19].} \mathrm{This} \mathrm{property} \mathrm{requires} \mathrm{longer} \mathrm{times} \mathrm{and} \mathrm{higher}$ quantities of water for pretreatment. In contrast to $\mathrm{Ca}(\mathrm{OH})_{2}, \mathrm{NaOH}$ is a strong alkali and requires much less water to dissolve and a lower reaction temperature [20]. $\mathrm{NaOH}$ pretreatment studies have been published for wheat straw, Miscanthus, and cotton stalk, showing the effects on delignification and enzymatic hydrolysis [21-23]. During alkaline pretreatment, some portions of the cellulose and hemicellulose are degraded and removed from the biomass by the action of hydroxide ions in addition to delignification [24-26]. A more desirable outcome would be removing as much of the lignin while retaining the fermentable sugars [27]. Therefore, conditions for alkaline pretreatment should be determined by comparing the amount of lignin removed as well as the fermentable sugar yields upon enzymatic hydrolysis.

One objective of this research was to compare the effects of pretreatment duration, source of alkali $\left(\mathrm{Ca}(\mathrm{OH})_{2}\right.$ and sodium hydroxide), and alkali loading on the delignification and enzymatic hydrolysis of rice straw. While many factors contribute to alkaline pretreatment [28], alkali use should be optimized to accomplish pretreatment, minimize waste treatment, and minimize working capital investment resulting from raw material costs. Temperature requirements influence capital investment equipment and manufacturing 
costs. Water use affects manufacturing costs and energy required to treat water that is not consumed in the process. Reducing water requirements has been identified as an important component in liquid fuel production from lignocellulosic biomass [29]. For these reasons and to offset the cost difference between $\mathrm{NaOH}$ and $\mathrm{Ca}(\mathrm{OH})_{2}$, the alkaline loading amount, pretreatment temperature, and water loading for $\mathrm{NaOH}$ pretreatment in this research were set at levels nearly half of those investigated for $\mathrm{Ca}(\mathrm{OH})_{2}$ pretreatment. To further investigate options for reducing water requirements, an additional objective was to examine the effects of post-pretreatment biomass washing on sugar yields upon enzymatic hydrolysis.

\section{Materials and Methods}

\section{Sample Preparation}

Fresh rice straw (Oryza sativa L., California rice M206) was collected a few hours after rice harvest from a field in the Central Valley of California $\left(38^{\circ} 43^{\prime} 21^{\prime \prime} \mathrm{N}\right.$ and $\left.121^{\circ} 35^{\prime} 39^{\prime \prime} \mathrm{W}\right)$. Electrically powered handheld hedge trimmers were used to harvest the rice straw. This method of harvest preserved the quality of straw and allowed for more uniformity by leaving 2 to 4 in. of straw stubble in the field. Straw was dried by forced aeration at room temperature for 1 week to $6.3 \%$ moisture $(93.7 \% \mathrm{wt} / \mathrm{wt}$ solid content). Air-dried rice straw was milled through a 2-mm mesh screen using a knife mill (Pulverisette 19, Fritsch, Germany). Prepared straw was stored in plastic bags at room temperature and was not washed before being subjected to pretreatment.

Alkaline Pretreatment

A full factorial experiment with parallel wash-only treatments was designed to investigate the alkaline loading and pretreatment time effects on delignification and sugar yield upon enzymatic hydrolysis. Studies with $\mathrm{Ca}(\mathrm{OH})_{2}$ were done at $95^{\circ} \mathrm{C}$, with a water loading of $10 \mathrm{~g} \mathrm{H}_{2} \mathrm{O} / \mathrm{g}$ air-dried rice straw, and an alkaline loading of 0,5 , and $10 \mathrm{wt} \%$ of oven dried rice straw. Studies with $\mathrm{NaOH}$ were done at $55^{\circ} \mathrm{C}$, with a water loading of $5 \mathrm{~g} \mathrm{H}_{2} \mathrm{O} / \mathrm{g}$ air-dried rice straw, and an alkaline loading of 0,2 , and $4 \mathrm{wt} \%$ of oven-dried rice straw. Pretreatment time varied from 1 to $3 \mathrm{~h}$. Pretreatment was done in reactors made from 250-mL HDPE containers (Nalgene Nunc International, Rochester, NY). Bulk S-grade hydrated $\mathrm{Ca}(\mathrm{OH})_{2}$ purchased from a local construction retail store and analytical grade sodium hydroxide were used in this study. Precisely weighed (16.2 g $\pm 0.1 \mathrm{mg}$, air-dried) rice straw was placed into each reactor after each weighing. For $\mathrm{Ca}(\mathrm{OH})_{2}$ pretreatment, biomass was blended thoroughly with the selected amount of hydrated $\mathrm{Ca}(\mathrm{OH})_{2}$ and distilled and deionized (DI) water in the reactor. The reactors were tightly capped and partially submerged in a boiling water bath for $10 \mathrm{~min}$ to allow for rapid heating. The reactors were then incubated at $95^{\circ} \mathrm{C}$ in a furnace with the reaction time determined by the experimental treatment. For $\mathrm{NaOH}$ pretreatment, sodium hydroxide was first dissolved in DI water to achieve the desired concentration and then preheated in an incubator at $55^{\circ} \mathrm{C}$. Once the temperature of the $\mathrm{NaOH}$ solution reached $55^{\circ} \mathrm{C}$, the solution was gradually mixed into rice straw contained in reactors. The reactors were capped tightly and then incubated in an isothermal incubator at $55^{\circ} \mathrm{C}$ for the designated reaction time. Neither the $\mathrm{Ca}(\mathrm{OH})_{2}$ pretreatments nor $\mathrm{NaOH}$ pretreatments were mixed during incubation. Pretreatment was terminated by quenching reactors in a room temperature water bath. For parallel wash-only treatments, rice straw was mixed with the same amount of DI water used in both 
pretreatments but without the addition of alkali. The wash-only reactors remained at room temperature for $3 \mathrm{~h}$, and then were handled using similar procedures as the pretreated samples.

\section{Handling of Pretreated Biomass and Associated Liquid}

For $\mathrm{Ca}(\mathrm{OH})_{2}$ pretreatment, pretreated biomass was first separated from the pretreatment liquid by filtration through predried $\left(105^{\circ} \mathrm{C}\right)$ and preweighed glass fiber filters $(\mathrm{G} 8,2 \mu \mathrm{m}$, Fisher Scientific Inc., Pittsburg, PA, USA). The pretreatment liquid was saved for measurement of $\mathrm{pH}$, soluble sugar content, soluble ash content, and total soluble solids. Residual solid samples were collected for determination of moisture content. Samples of filtered pretreated biomass (moisture content around $80 \%$ wet basis) were taken and placed in $20-\mathrm{mL}$ glass sample vials as unwashed pretreated biomass for later enzymatic hydrolysis. A corresponding portion of pretreatment liquid was added to the unwashed pretreated biomass samples immediately before enzymatic hydrolysis to simulate the case of direct enzymatic hydrolysis of pretreated biomass solids and liquids. Because of the relative low solubility of $\mathrm{Ca}(\mathrm{OH})_{2}$ at low temperature and low water content, unwashed $\mathrm{Ca}(\mathrm{OH})_{2}$-pretreated samples were not neutralized until enzymatic hydrolysis $[15,17]$. Solid recovery was calculated from a mass balance on the dry solids in solid and liquid fractions. The remaining biomass was subjected to a wash process described in the next section. All biomass and liquid samples were stored at $4^{\circ} \mathrm{C}$ between each stage of post-pretreatment analysis.

Due to the $\mathrm{NaOH}$ pretreatments containing no free water after the experiment, the $\mathrm{pH}$ of the pretreated biomass was measured using $\mathrm{pH}$ paper. Then, the biomass was neutralized to $\mathrm{pH} 7$ to 8 by gradually adding $0.3 \mathrm{~N} \mathrm{HCl}$ to stop the reaction associated with residual $\mathrm{NaOH}$. Samples of neutralized, pretreated biomass (moisture content around $80 \%$ ) were taken and placed in $20-\mathrm{mL}$ glass sample vials as unwashed pretreated biomass for later enzymatic hydrolysis. Sterilized DI water was added to the remaining neutralized biomass at $10 \mathrm{~g} \mathrm{H}_{2} \mathrm{O} / \mathrm{g}$ dry straw to remove and determine the soluble components after pretreatment. The liquid separation, unwashed biomass handling, and sample analysis and storage followed the same procedure described for $\mathrm{Ca}(\mathrm{OH})_{2}$-pretreated samples.

\section{Biomass Washing}

The residual biomass remaining from the initial pretreatment liquid separation was washed with DI water until the effluent liquid filtrate was clear. The total volume of DI water used to wash approximately 16 -g dry rice straw was $1.3 \mathrm{~L}$ for $\mathrm{Ca}(\mathrm{OH})_{2}$-pretreated biomass and $1.5 \mathrm{~L}$ for $\mathrm{NaOH}$-pretreated biomass. The wash water was separated from rice straw by filtration through preweighed and predried $\left(105^{\circ} \mathrm{C}\right)$ glass fiber filters (Pall Gelman Type A/E, Pall Corporation, Port Washington, NY, USA). The filters and reactors were dried at $105^{\circ} \mathrm{C}$ for determination of biomass on the filter and the residues left in the reactor. Samples were collected to determine moisture content. Total washed biomass was calculated to determine the loss of biomass during the wash step. Samples of the filtered and washed biomass were transferred to $20-\mathrm{mL}$ glass sample vials as washed, pretreated biomass and were stored at $4{ }^{\circ} \mathrm{C}$ prior to enzymatic hydrolysis.

\section{Enzymatic Hydrolysis}

Enzymatic hydrolysis of alkaline-pretreated rice straw was performed in sterilized $125-\mathrm{mL}$ flasks. The solid level was initially set at $4 \% \mathrm{wt} / \mathrm{wt}$ of the total reaction, which corresponds 
to a glucose concentration of $1.1 \%$ to $1.4 \%$, for all reactions based on recommendations from the enzyme supplier. The $\mathrm{pH}$ of pretreated materials in the flasks was first adjusted to 5.0 with glacial acetic acid, and $1 \mathrm{M}$ sodium citrate buffer $(\mathrm{pH} 4.5)$ was added with sterilized DI water to a final buffer concentration of $0.05 \mathrm{M}$. Tetracycline $(40 \mu \mathrm{g} / \mathrm{mL})$ and chloramphenicol $(50 \mu \mathrm{g} / \mathrm{mL})$ were added to prevent microbial growth during the reaction period. Cellulase (Celluclast 1.5 L; Novozymes, Franklinton, NC) and $\beta$-glucosidase (Novo 188 , Novozymes) were added at 15 filter paper unit (FPU)/g glucose and 15 cellobiose unit $(\mathrm{CBU}) / \mathrm{g}$ glucose, respectively. The enzyme activities were determined prior to hydrolysis according to Ghose [1]. The enzyme dosage was selected based on economic preference and the results of previous publications [17, 31, 32]. Enzymes were loaded based on a pergram-of-glucose basis because of the possibility of free sugars released during pretreatment and sugars remaining in unwashed samples affecting activity. The reaction mixtures were shaken at $50^{\circ} \mathrm{C}$ and $150 \mathrm{rpm}$ for 3 days. Samples $(1.5 \mathrm{~mL})$ were withdrawn at the beginning of the reaction and every $24 \mathrm{~h}$. Samples were first incubated on a dry heating bath at $105^{\circ} \mathrm{C}$ for $15 \mathrm{~min}$ to inactivate enzymes, centrifuged at 5,000 $\mathrm{g}$ for $5 \mathrm{~min}$, and then filtered directly into autosampler vials.

\section{Analytical Methods}

The solid, moisture and ash contents of biomass and liquid samples were determined by methods adapted from NREL CAT Task Laboratory Analytical Procedure \#001 and \#005 $[33,34]$. The solid recovery yield of biomass (SR) is provided in Tables 1 and 2. Acidinsoluble and acid-soluble lignins and carbohydrate contents were determined using methods adapted from NREL CAT Task Laboratory Analytical Procedure \#003 [35], \#004 [36], and \#002 [37], respectively. A high-pressure liquid chromatography system (Prominence HPLC standard automated system; Shimadzu Scientific Instruments, Columbia, MD) equipped with an autosampler (SIL-20A/C) and a refractive index detector was used for determination of sugars. The content of individual sugars in the filtrate from the lignin assay was determined using an Aminex HPX-87P column with a de-ashing and Carbo-P guard cartage (BioRad, Hercules, CA). Analyses were run at $85^{\circ} \mathrm{C}$ at $0.6 \mathrm{~mL} / \mathrm{min}$ using $0.45-\mu \mathrm{m}$ filtered sterilized DI water as the mobile phase. Pretreated liquid and enzymatic hydrolysis samples were analyzed using an Aminex HPX-87H with a de-ashing and Cation- $\mathrm{H}$ guard cartage (BioRad.). Analyses were run at $65^{\circ} \mathrm{C}$ at $0.6 \mathrm{~mL} / \mathrm{min}$ using $5 \mathrm{mM}$ $\mathrm{H}_{2} \mathrm{SO}_{4}$ as the mobile phase. Peaks detected were identified and quantified using authentic calibration standards.

\section{Data Analysis}

For statistical analysis of factor effects, the factor levels used in both experiments were converted to a coding scale of 1 and -1 , where 1 indicates the highest level and -1 indicates the lowest level (Tables 1 and 2). Results from full factorial studies were analyzed using JMP IN v.7 (SAS Institute, Cary, NC) to determine if alkaline loading and time had significant effects on delignification, glucose recovery, and glucose yield using Eq. 1:

$$
E\{Y\}=\beta_{0}+\beta_{1} X_{1}+\beta_{2} X_{2}+\beta_{12} X_{1} X_{2}+\beta_{11} X_{1}^{2}+\beta_{22} X_{2}^{2}
$$

where $E\{Y\}$ is the expected value of the response variable, $\beta_{0}$ is the model intercept, $X_{1}$ is the coded level $(-1,1)$ for alkaline loading, $X_{2}$ is the coded level $(-1,1)$ for reaction time, $\beta_{1}$ is the parameter estimate for alkaline loading, $\beta_{2}$ is the parameter estimate for reaction time, 


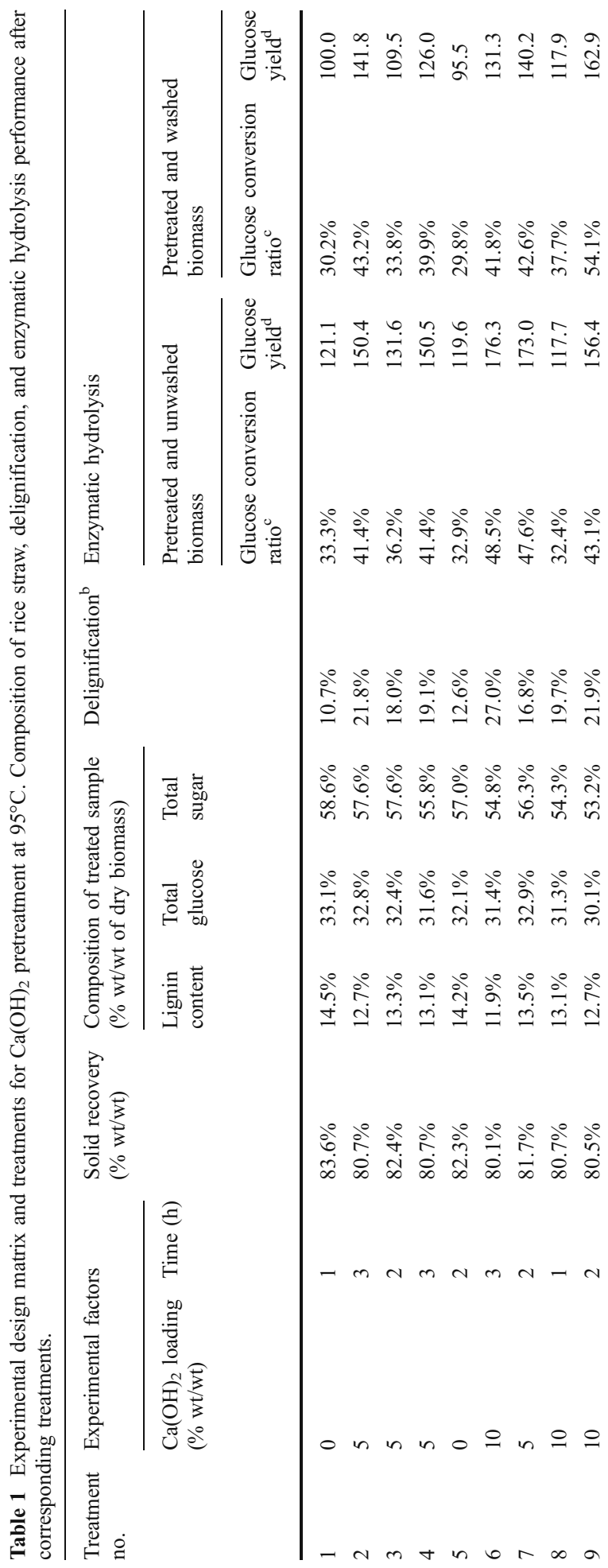




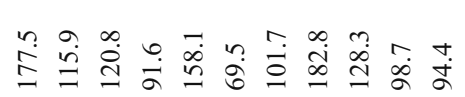
迥

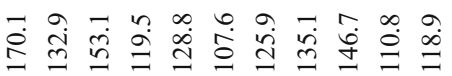
ஓ 实

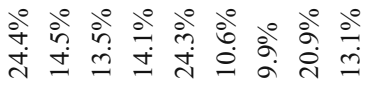

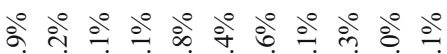

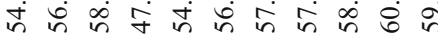

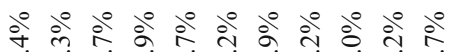
ल ते

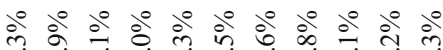

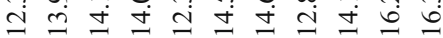

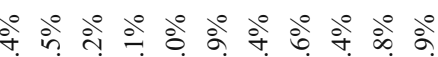

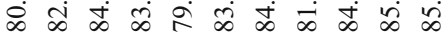
$m m-m n-n-m-1$

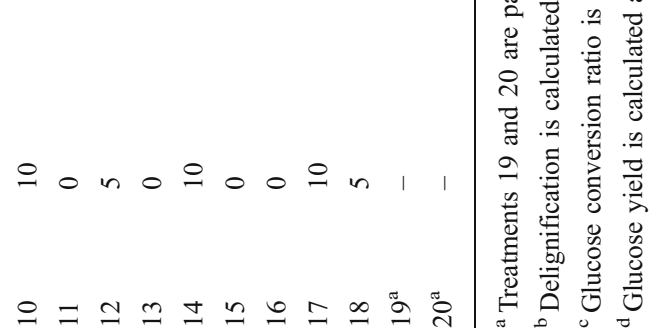




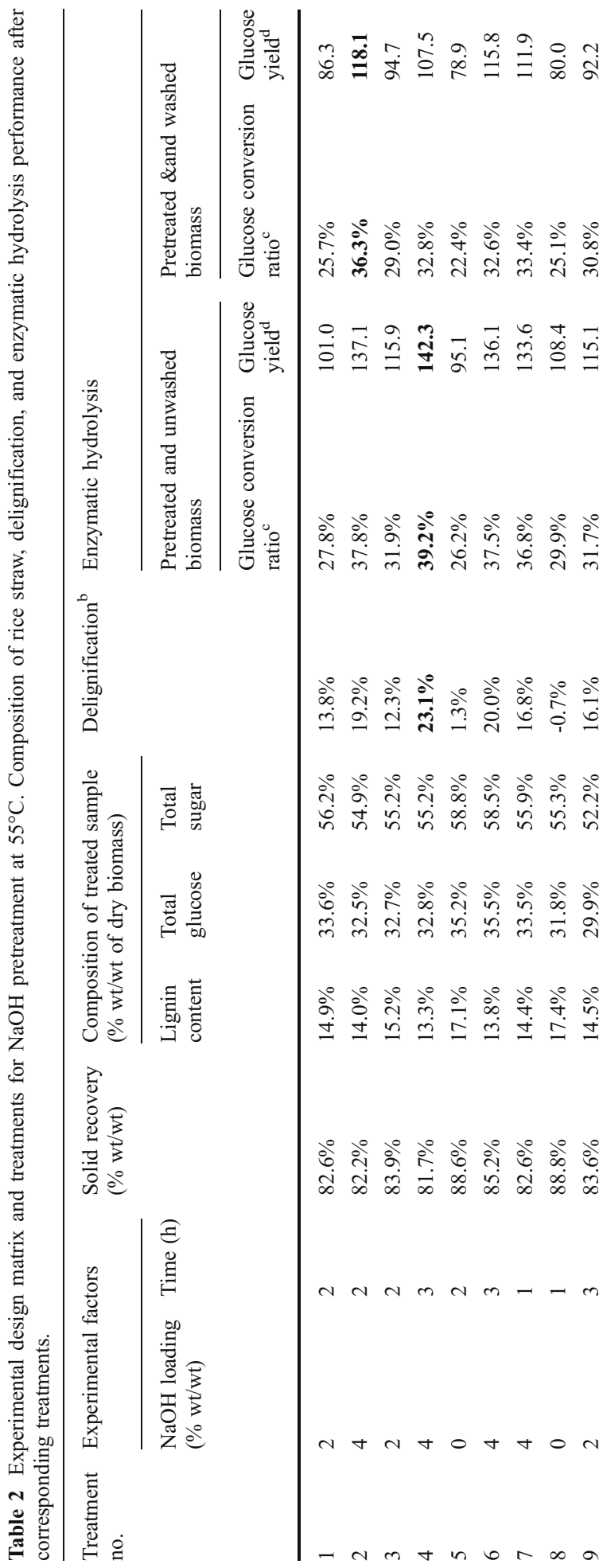




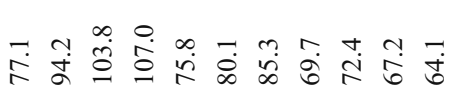

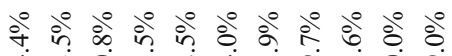

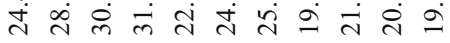

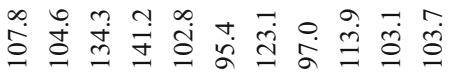

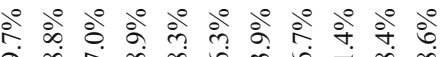

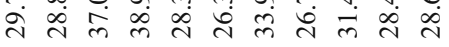

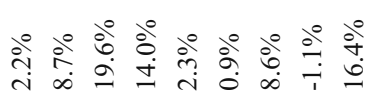

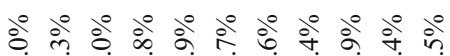

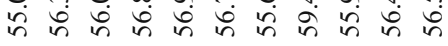

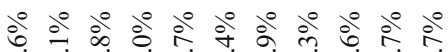

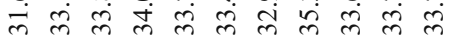

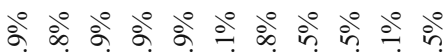
ம்

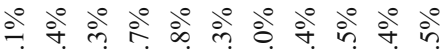

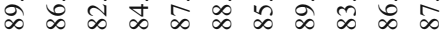

$m-N-N m-m \mid$

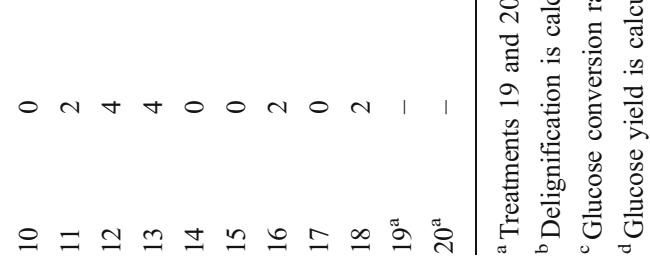

.

$\stackrel{0 D}{\Xi}$

药 
$\beta_{12}$ is the parameter estimate for the interaction between alkaline loading and reaction time, $\beta_{11}$ is the parameter estimate representing second-order effects of alkaline loading, and $\beta_{22}$ is the parameter estimate representing second-order effects of reaction time. Reduced models were determined for all response variables using mixed stepwise regression in JMP IN.

\section{Results and Discussion}

\section{Compositional Changes of Rice Straw After Alkaline Pretreatment}

In order to compare the composition difference between raw and pretreated rice straw, the composition of the raw rice straw was first analyzed. The main components included carbohydrates, which made up $61.85 \% \mathrm{wt} / \mathrm{wt}$ of the dry biomass and included glucose (36.32\% wt/wt of the dry biomass) and xylose (19.45\% wt/wt of the dry biomass). The ash and lignin contents were $18.01 \% \mathrm{wt} / \mathrm{wt}$ and $17.6 \% \mathrm{wt} / \mathrm{wt}$ of the dry biomass, respectively. The lignin content was separated into acid-soluble $(3.53 \% \mathrm{wt} / \mathrm{wt}$ of dry biomass) and acidinsoluble (14.07\% wt/wt of dry biomass) components.

The sugar content decreased in all experimental treatments including wash-only treatments (Tables 1 and 2). An interesting observation in this study was that $\mathrm{NaOH}-$ pretreated biomass was relatively difficult to filter after pretreatment and washing. However, the delignification level and sugar lost upon $\mathrm{NaOH}$ pretreatment were not higher than those measured in $\mathrm{Ca}(\mathrm{OH})_{2}$ pretreatment. A probable reason for the increase in filtration difficulty is that $\mathrm{NaOH}$ pretreatment was performed at a lower water content and resulted in higher concentrations of nondegradation, nonsoluble small fragments and silica, which would also be released from rice straw during pretreatment with $\mathrm{NaOH}$ [38].

\section{The Effects of Experimental Factors on Delignification}

Several previous studies that have examined $\mathrm{Ca}(\mathrm{OH})_{2}$ pretreatment indicated that an increase in $\mathrm{Ca}(\mathrm{OH})_{2}$ loading has a limited effect on lignin removal when $\mathrm{Ca}(\mathrm{OH})_{2}$ loading is over $10 \% \mathrm{wt} / \mathrm{wt}$ of the dry weight of the biomass [16, 39-41]. Most $\mathrm{Ca}(\mathrm{OH})_{2}$ pretreatment studies have been done using higher lignin content biomass and have been performed for longer periods $[17,40]$. Since rice straw has a lower lignin content compared to other biomass sources, this work focused on investigating pretreatment effects using shorter periods with different alkaline agents. The results from the present study showed that both alkaline loading and reaction time increased delignification (Tables 1 and 2 and Fig. 1). The effects of alkaline loading and reaction time were statistically significant (Table 3); however, there was no significant interaction between loading and time on delignification. $\mathrm{Ca}(\mathrm{OH})_{2}$ pretreatment performed at $95^{\circ} \mathrm{C}$ resulted in delignification levels as high as $27 \% \mathrm{wt} / \mathrm{wt}$ relative to average lignin removed in the wash-only treatments, while $\mathrm{NaOH}$ pretreatment performed at $55^{\circ} \mathrm{C}$ had maximum delignification levels of $23 \%$ (Fig. 1). The alkaline loading amount, water loading, and reaction temperature for $\mathrm{NaOH}$ pretreatment were only approximately half of those levels tested in $\mathrm{Ca}(\mathrm{OH})_{2}$ pretreatment. Heating and water requirements are important in large-scale processes because they are linked to capital and operating costs. Thus, in addition to biomass delignification, it is important to further investigate enzymatic hydrolysis yields and perform an economic analysis to compare both pretreatments.

The results also show that straw pretreatment at $10 \mathrm{~g} \mathrm{H}_{2} \mathrm{O} / \mathrm{g}$ straw and $95^{\circ} \mathrm{C}$ had significantly greater delignification $(p<0.0001)$ compared to pretreatment at $5 \mathrm{~g} \mathrm{H}_{2} \mathrm{O} / \mathrm{g}$ 
Fig. 1 Effect of alkaline loading and reaction time on delignification of rice straw upon a $\mathrm{Ca}(\mathrm{OH})_{2}$ pretreatment at $95^{\circ} \mathrm{C}$ and

b $\mathrm{NaOH}$ pretreatment and $55^{\circ} \mathrm{C}$
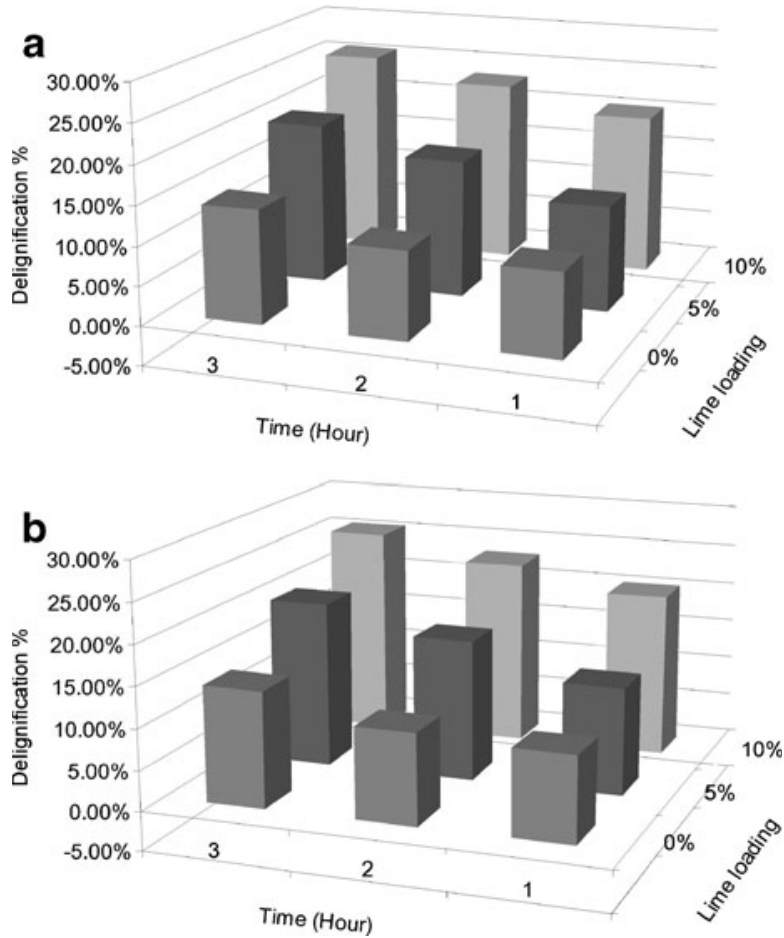

straw and $55^{\circ} \mathrm{C}$; average delignification was $12 \%$ and $0.8 \%$, respectively. Thus, the net delignification effect associated with $\mathrm{Ca}(\mathrm{OH})_{2}$ in the $\mathrm{Ca}(\mathrm{OH})_{2}$ pretreatment studies in this work may be on a par with the delignification effect from $\mathrm{NaOH}$ during $\mathrm{NaOH}$ pretreatment. Other studies have examined hot water pretreatment of lignocellulosic biomass and showed the effects on delignification and xylan dissolution [42-44]. However, those studies were performed at higher temperatures $\left(170-220{ }^{\circ} \mathrm{C}\right)$ for shorter periods. Further investigation of the effect of hot water treatment at relatively milder temperatures

Table 3 Statistical analysis of alkaline loading and pretreatment time on delignification.

\begin{tabular}{|c|c|c|c|c|}
\hline \multirow[t]{2}{*}{ Factor } & \multicolumn{2}{|c|}{$\mathrm{Ca}(\mathrm{OH})_{2}$ pretreatment } & \multicolumn{2}{|c|}{$\mathrm{NaOH}$ pretreatment } \\
\hline & Estimate $^{\mathrm{a}, \mathrm{b}}$ & $p$ value & Estimate $^{\mathrm{a}, \mathrm{c}}$ & $p$ value \\
\hline Alkaline loading & 5.5 & $<0.0001$ & 8.99 & $<0.0001$ \\
\hline Time & 2.7 & $<0.0001$ & 2.71 & $<0.0001$ \\
\hline Alkaline loading * time & & & 0.935 & 0.0568 \\
\hline Alkaline loading * alkaline loading & & & -2.83 & 0.0007 \\
\hline Time * time & & & -0.99 & 0.143 \\
\hline
\end{tabular}

${ }^{\text {a }}$ Estimates not listed had $p$ value $>0.25$ and were removed during stepwise regression

${ }^{\mathrm{b}}$ The $R^{2}$ value for the model was 0.94

${ }^{\mathrm{c}}$ The $R^{2}$ value for the model was 0.98 
$\left(\sim 100^{\circ} \mathrm{C}\right)$ with different variables, such as time and water levels, should be considered for pretreatment of rice straw.

The Effect of Experimental Factors on Sugar Yield Upon Enzymatic Hydrolysis

The presence of alkali during pretreatment of rice straw at $55^{\circ} \mathrm{C}$ or $95^{\circ} \mathrm{C}$ increased the glucose conversion ratio and glucose yield from the raw biomass upon $72 \mathrm{~h}$ of enzymatic hydrolysis when compared to wash-only treatments (Tables 1 and 2 and Figs. 2 and 3). The maximum glucose conversion ratios as well as glucose yields were all obtained with the highest level of alkaline loading in both pretreatments but not necessarily with highest level of pretreatment time; the highest ratios and yields for washed biomass from $\mathrm{Ca}(\mathrm{OH})_{2}$ pretreatment were $56 \% \mathrm{wt} / \mathrm{wt}$ of the solid fraction of pretreated biomass glucose content and $183 \mathrm{mg} / \mathrm{g}$ initial glucose content in the raw material, respectively (Fig. 2), while the highest ratios and yields for washed biomass from $\mathrm{NaOH}$ pretreatment were $36 \% \mathrm{wt} / \mathrm{wt}$ of the solid fraction of pretreated biomass glucose content and $118 \mathrm{mg} / \mathrm{g}$ initial glucose content in the raw material, respectively (Fig. 3). Statistical analyses of the data indicate that alkaline loading had the most significant effect on the enzymatic hydrolysis of pretreated rice straw (Tables 4, 5, 6 and 7). The results here are consistent with other studies investigating alkaline pretreatment of other lignocellulosic materials [39, 45]. For example, in Saha's report [15-18], $\mathrm{Ca}(\mathrm{OH})_{2}$ dose had a more significant effect on enzymatic hydrolysis compared to pretreatment time when the reaction was performed at $121^{\circ} \mathrm{C}$ and

Fig. 2 Effect of alkaline loading and reaction time on 3-day enzymatic hydrolysis sugar yield from rice straw upon $\mathrm{Ca}(\mathrm{OH})_{2}$ pretreatment at $95^{\circ} \mathrm{C}$ where a provides yields for unwashed straw and $\mathbf{b}$ for washed straw
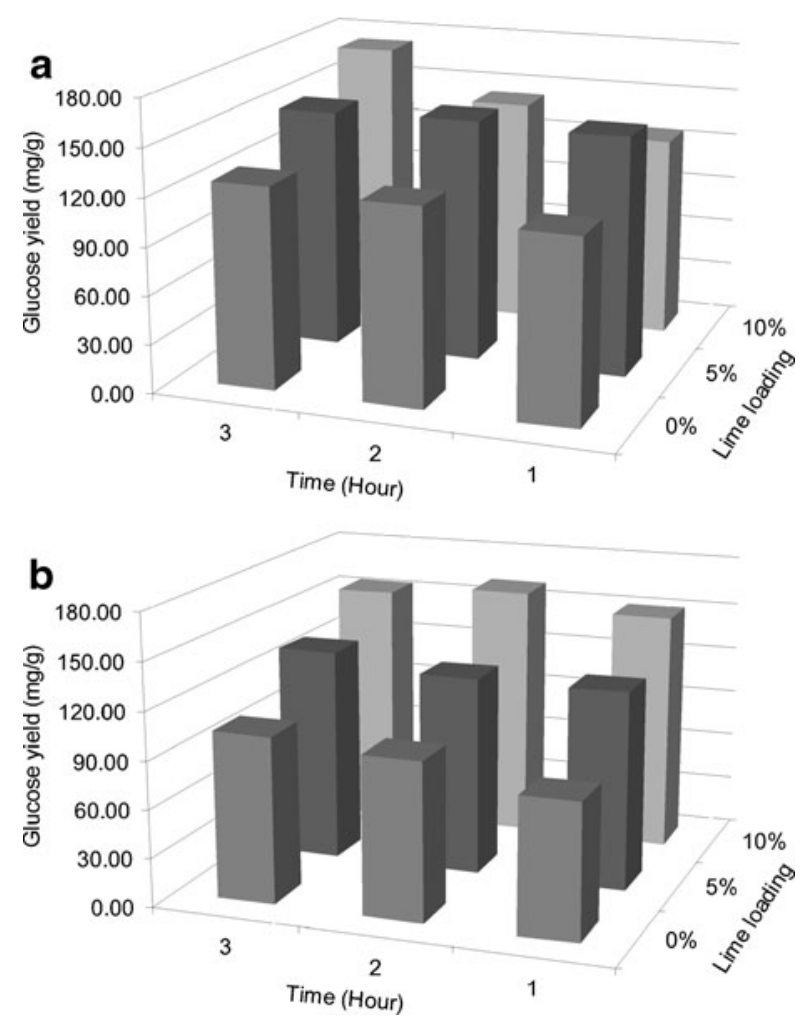
Fig. 3 Effect of alkaline loading and reaction time on 3-day enzymatic hydrolysis sugar yield from rice straw upon $\mathrm{NaOH}$ pretreatment at $55^{\circ} \mathrm{C}$ where a provides yields for unwashed straw and $\mathbf{b}$ for washed straw
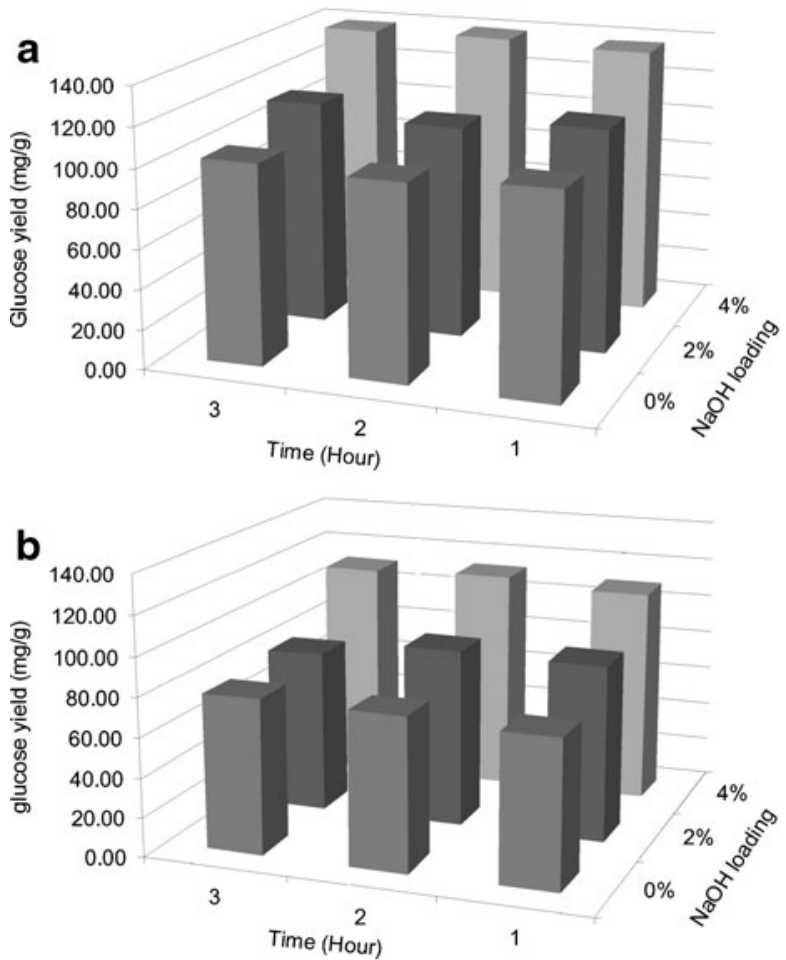

wheat straw was used as the feedstock. The results suggest that pretreatment at a higher loading level and higher temperature may improve sugar yields upon enzymatic hydrolysis.

\section{Post-pretreatment Washing Effect on Enzymatic Hydrolysis}

One purpose of the wash step after pretreatment is to remove the alkali residues and inhibitors formed during pretreatment that might hinder enzymatic hydrolysis and microbial fermentation [46, 47]. In the washed samples, the concentration of sodium and calcium ions

Table 4 Statistical analysis of effects of alkaline loading and pretreatment time on glucose conversion ratio measured after 3 days of enzymatic hydrolysis, $\mathrm{Ca}(\mathrm{OH})_{2}$ pretreatment at $95^{\circ} \mathrm{C}$.

\begin{tabular}{|c|c|c|c|c|}
\hline \multirow[t]{2}{*}{ Factor in $\mathrm{Ca}(\mathrm{OH})_{2}$ pretreatment } & \multicolumn{2}{|c|}{ Pretreated and unwashed } & \multicolumn{2}{|c|}{ Pretreated and washed } \\
\hline & Estimate $^{\mathrm{a}, \mathrm{b}}$ & $p$ value & Estimate $^{\mathrm{a}, \mathrm{c}}$ & $p$ value \\
\hline Alkaline loading & 3.62 & 0.0043 & 9.40 & $<0.0001$ \\
\hline Time & 2.71 & 0.0229 & 2.77 & 0.0838 \\
\hline Alkaline loading $*$ time & 2.40 & 0.0844 & & \\
\hline Alkaline loading * alkaline loading & -4.48 & 0.0258 & & \\
\hline Time $*$ time & & & & \\
\hline
\end{tabular}

\footnotetext{
${ }^{\text {a }}$ Estimates not listed had $p$ value $>0.25$ and were removed during stepwise regression

${ }^{\mathrm{b}}$ The $R^{2}$ value for the model was 0.69

${ }^{\mathrm{c}}$ The $R^{2}$ value for the model was 0.74
}

\section{㴆: Humana Press}


Table 5 Statistical analysis of effects of alkaline loading and pretreatment time on glucose conversion ratio measured after 3 days of enzymatic hydrolysis, $\mathrm{NaOH}$ pretreatment at $55^{\circ} \mathrm{C}$.

\begin{tabular}{|c|c|c|c|c|}
\hline \multirow[t]{2}{*}{ Factor in $\mathrm{NaOH}$ pretreatment } & \multicolumn{2}{|c|}{ Pretreated and unwashed } & \multicolumn{2}{|c|}{ Pretreated and washed } \\
\hline & Estimate $^{\mathrm{a}, \mathrm{b}}$ & $p$ value & Estimate $^{\mathrm{a}, \mathrm{c}}$ & $p$ value \\
\hline Alkaline loading & 5.00 & $<0.0001$ & 4.93 & $<0.0001$ \\
\hline \multicolumn{5}{|l|}{ Time } \\
\hline \multicolumn{5}{|l|}{ Alkaline loading $*$ time } \\
\hline Alkaline loading * alkaline loading & 1.93 & 0.0392 & & \\
\hline Time $*$ time & & & & \\
\hline
\end{tabular}

${ }^{\mathrm{a}}$ Estimates not listed had $\mathrm{p}$ value $>0.25$ and were removed during stepwise regression

${ }^{\mathrm{b}}$ The $R^{2}$ value for the model was 0.87

${ }^{\mathrm{c}}$ The $R^{2}$ value for the model was 0.77

Table 6 Statistical analysis of alkaline loading and pretreatment time on glucose yield after 3 days of enzymatic hydrolysis, $\mathrm{Ca}(\mathrm{OH})_{2}$ pretreatment at $95^{\circ} \mathrm{C}$.

\begin{tabular}{|c|c|c|c|c|}
\hline \multirow[t]{2}{*}{ Factor in $\mathrm{Ca}(\mathrm{OH})_{2}$ pretreatment } & \multicolumn{2}{|c|}{ Pretreated and unwashed } & \multicolumn{2}{|c|}{ Pretreated and washed } \\
\hline & Estimate $^{\mathrm{a}, \mathrm{b}}$ & $p$ value & Estimate $^{\mathrm{a}, \mathrm{c}}$ & $p$ value \\
\hline Alkaline loading & 13.15 & 0.0043 & 29.69 & $<0.0001$ \\
\hline Time & 9.85 & 0.023 & & \\
\hline Alkaline loading $*$ time & 8.73 & 0.084 & & \\
\hline Alkaline loading * alkaline loading & -16.62 & 0.026 & & \\
\hline Time $*$ time & & & & \\
\hline
\end{tabular}

${ }^{\text {a }}$ Estimates not listed had $p$ value $>0.25$ and were removed during stepwise regression

${ }^{\mathrm{b}}$ The $R^{2}$ value for the model was 0.68

${ }^{\mathrm{c}}$ The $R^{2}$ value for the model was 0.67

Table 7 Statistical analysis of alkaline loading and pretreatment time on glucose yield after 3 days of enzymatic hydrolysis, $\mathrm{NaOH}$ pretreatment at $55^{\circ} \mathrm{C}$.

\begin{tabular}{|c|c|c|c|c|}
\hline \multirow[t]{2}{*}{ Factor in $\mathrm{NaOH}$ pretreatment } & \multicolumn{2}{|c|}{ Pretreated and unwashed } & \multicolumn{2}{|c|}{ Pretreated and washed } \\
\hline & Estimate $^{\mathrm{a}, \mathrm{b}}$ & $p$ value & Estimate $^{\mathrm{a}, \mathrm{c}}$ & $p$ value \\
\hline Alkaline loading & 18.17 & $<0.0001$ & 16.86 & $<0.0001$ \\
\hline \multicolumn{5}{|l|}{ Time } \\
\hline \multicolumn{5}{|l|}{ Alkaline loading $*$ time } \\
\hline $\begin{array}{l}\text { Alkaline loading * alkaline loading } \\
\text { Time * time }\end{array}$ & 7.02 & 0.039 & 6.30 & 0.061 \\
\hline
\end{tabular}

${ }^{\text {a }}$ Estimates not listed had $p$ value $>0.25$ and were removed during stepwise regression

${ }^{\mathrm{b}}$ The $R^{2}$ value for the model was 0.87

${ }^{\mathrm{c}}$ The $R^{2}$ value for the model was 0.86 
should be extremely low or absent because of the intensive wash procedure. However, in the unwashed samples, the sodium and calcium remained with the biomass in the pretreatment liquid, so the concentration of sodium and calcium ions should be similar to the initial loaded in the reaction. For $\mathrm{Ca}(\mathrm{OH})_{2}$-pretreated rice straw, a higher maximum glucose conversion ratio was achieved by applying the post-pretreatment washing step (Table 1 and Fig. 2). The difference in conversion ratio indicates that there are enzyme inhibitors associated with $\mathrm{Ca}(\mathrm{OH})_{2}$ pretreatment that can be removed by washing. Enzyme inhibition may have been due to residual $\mathrm{Ca}(\mathrm{OH})_{2}$ in unwashed straw or inhibitors formed at higher temperature and longer reaction times. In this study, washing significantly improved glucose conversion $(p=0.0017)$ and glucose yield $(p=0.0013)$ with increasing $\mathrm{Ca}(\mathrm{OH})_{2}$ loading levels. The results suggest that residual nonreacted $\mathrm{Ca}(\mathrm{OH})_{2}$ or other inhibitors formed during calcium hydroxide pretreatment have a negative effect on enzymatic hydrolysis. In $\mathrm{NaOH}-$ pretreated samples, employment of the post-pretreatment washing step did not significantly increase glucose conversion (Fig. 3). In contrast to $\mathrm{Ca}(\mathrm{OH})_{2}$-pretreated samples, $\mathrm{NaOH}$ pretreatment apparently did not produce inhibitors to enzyme activity. The lack of inhibition may have been due to the lower temperature employed in this method, the different cation, or that lower levels of $\mathrm{Na}$ ions were present in pretreated samples compared to $\mathrm{Ca}$ ions. The overall glucose yields were greater in unwashed $\mathrm{NaOH}$-pretreated rice straw compared to washed $\mathrm{NaOH}$-pretreated rice straw, likely due to sugars being lost during the washing step (Table 2).

\section{Conclusions}

Both $\mathrm{Ca}(\mathrm{OH})_{2}$ pretreatment performed at $95^{\circ} \mathrm{C}$ and $\mathrm{NaOH}$ pretreatment performed at $55^{\circ} \mathrm{C}$ showed that increasing both alkaline loading and reaction time significantly improved delignification, but only an increase in alkaline loading improved enzymatic hydrolysis. Also, the post-pretreatment wash step improved the enzymatic glucose conversion ratio for $\mathrm{Ca}(\mathrm{OH})_{2}$-pretreated samples but had no effect on overall glucose yield. For $\mathrm{NaOH}-$ pretreated samples, unwashed samples had equivalent glucose conversion ratios and higher glucose yields, indicating promising opportunities for high solids, low water input pretreatment, and conversion of rice straw. Although $\mathrm{Ca}(\mathrm{OH})_{2}$ pretreatment in this study yielded the highest glucose conversion ratios and glucose yields, higher temperatures were employed in comparison to $\mathrm{NaOH}$ pretreatment. The requirement for washing $\mathrm{Ca}(\mathrm{OH})_{2}$ pretreated rice straw may make this source of alkali unfavorable on a large scale. Temperature and water requirements will directly affect the cost of equipment, operation, energy, and wastewater treatment, which will play significant roles in the economic viability of an industrial scale process. The specific alkali used and loading amount not only affect the cost of materials but also affect the alkali recovery operations. Thus, an economic analysis based on the results of this study is necessary for developing the best alkaline pretreatment process on a large scale.

Acknowledgement Funding for this research was provided by Chevron Technology Ventures (Houston, Texas, USA). The authors thank Kameron Chun for assistance with analytical methods.

Open Access This article is distributed under the terms of the Creative Commons Attribution Noncommercial License which permits any noncommercial use, distribution, and reproduction in any medium, provided the original author(s) and source are credited. 


\section{References}

1. Energy Independence and Security Act of 2007, Senate and House of Representatives of the United States of America.

2. Kim, S., \& Dale, B. E. (2004). Biomass and Bioenergy, 26, 361-375.

3. Food and Agricultural Organization of the United Nations (FAOSTAT) 2007. Available from: http:// faostat.fao.org/site/567/default.aspx\#ancor. Accessed December 1, 2009.

4. Kadam, K. L., Forrest, L. H., \& Jacobson, W. A. (2000). Biomass and Bioenergy, 18, 369-389.

5. Summers, M. D., Hydeb, P. R. \& Jenkins, B. M. (2001). Yields and property variations for rice straw in California, 5th International Biomass Conference of the Americas Orlando, Florida, USA.

6. Theoretical ethanol yield calculator 2006. Available from: http://www1.eere.energy.gov/biomass/ ethanol_yield_calculator.html Accessed December 1, 2009.

7. Petroleum consumption by type of refined petroleum product 2005. Available from: http://www.eia.doe. gov/pub/international/iea2006/table35.xls. Accessed December 1, 2009.

8. Mosier, N., Wyman, C. E., Dale, B., Elander, R., Lee, Y. Y., Holtzapple, M. T., et al. (2005). Bioresource Technology, 96, 673-686.

9. Yang, B., \& Wyman, C. E. (2008). Biofuels. Bioproducts and Biorefining, 2, 26-40.

10. Hendriks, A. T., \& Zeeman, G. (2009). Bioresource Technology, 100, 10-18.

11. Taherzadeh, M. J., \& Karimi, K. (2008). International Journal of Molecular Sciences., 9, 1621-1651.

12. Bobleter, O. (1994). Progress in Polymer Science, 19, 797-841.

13. Sun, Y., \& Cheng, J. (2002). Bioresource Technology, 83, 1-11.

14. Fan, L. T., Gharpuray, M. M., \& Lee, Y. H. (1987). Cellulose hydrolysis. Biotechnology monographs. New York: Springer.

15. Chang, V., Burr, B., \& Holtzapple, M. T. (1997). Applied Biochemistry and Biotechnology, 63-65, 3-19.

16. Chang, V., Nagwani, M., \& Holtzapple, M. T. (1998). Applied Biochemistry and Biotechnology, 74, 135159.

17. Kim, S., \& Holtzapple, M. T. (2005). Bioresource Technology, 96, 1994-2006.

18. Saha, B. C., \& Cotta, M. A. (2008). Biomass and Bioenergy, 32, 971-977.

19. Oates, J. A. H. (2007). Lime and Limestone 207-211.

20. Sun, R., Lawther, J. M., \& Banks, W. B. (1996). Journal of Applied Polymer Science, 62, 1473-1481.

21. Bjerre, A. B., Olesen, A. B., Fernqvist, T., Ploger, A., \& Schmidt, A. S. (1996). Biotechnology and Bioengineering, 49, 568-577.

22. de Vrije, T., de Haas, G. G., Tan, G. B., Keijsers, E. R. P., \& Claassen, P. A. M. (2002). International Journal of Hydrogen Energy, 27, 1381-1390.

23. Silverstein, R. A., Chen, Y., Sharma-Shivappa, R. R., Boyette, M. D., \& Osborne, J. (2007). Bioresource Technology, 98, 3000-3011.

24. Klinke, H. B., Ahring, B. K., Schmidt, A. S., \& Thomsen, A. B. (2002). Bioresource Technology, 82, 15-26.

25. Knill, C. J., \& Kennedy, J. F. (2003). Carbohydrate Polymers, 51, 281-300.

26. Sjöström, E. (1991). Biomass and Bioenergy, 1, 61-64.

27. Chandra, R., Bura, R., Mabee, W., Berlin, A., Pan, X., \& Saddler, J. (2007). Advances in Biochemical Engineering, Biotechnology, 108, 67-93.

28. Kaar, W. E., \& Holtzapple, M. T. (2000). Biomass and Bioenergy, 18, 189-199.

29. Gerbens-Leenes, W., Hoekstra, A. Y., \& van der Meer, T. H. (2009). Proceedings of the National Academy of Sciences of the United States of America., 106, 10219-10223.

30. Ghose, T. K. (1987). Pure and Applied Chemistry, 59, 257-268.

31. Wyman, C. E., Dale, B. E., Elander, R. T., Holtzapple, M., Ladisch, M. R., \& Lee, Y. Y. (2005). Bioresource Technology, 96, 2026-2032.

32. Zheng, Y., Pan, Z., Zhang, R., \& Wang, D. (2009). Applied Energy, 86, 2459-2465.

33. Ehrman, T. (1992). NREL CAT Task Laboratory Analytical Procedure \#005.

34. Ehrman, T. (1994). NREL CAT Task Laboratory Analytical Procedure \#001.

35. Templeton, D., \& Ehrman, T. (1995). NREL CAT Task Laboratory Analytical Procedure \#003.

36. Ehrman, T. (1996). NREL CAT Task Laboratory Analytical Procedure \#004.

37. Ruiz, R. \& Ehrman, T. (1996) NREL CAT Task Laboratory Analytical Procedure \#002.

38. Jackson, M. G. (1977). Animal Feed Science and Technology, 2, 105-130.

39. Saha, B. C., \& Cotta, M. A. (2007). Journal of Chemical Technology and Biotechnology, 82, 913-919.

40. Chang, V., Nagwani, M., Kim, C.-H., \& Holtzapple, M. T. (2001). Applied Biochemistry and Biotechnology, 94, 1-28.

41. Kim, S. H. (2005). Lime pretreatment and enzymatic hydrolysis of corn stover, Chemical Engineering. College station: Texas A\&M University.

42. Yang, B., \& Wyman, C. E. (2004). Biotechnology and Bioengineering, 86, 88-98. 
43. Kim, T. H., \& Lee, Y. Y. (2006). Bioresource Technology, 97, 224-232.

44. Laser, M., Schulman, D., Allen, S. G., Lichwa, J., Antal, M. J., \& Lynd, L. R. (2002). Bioresource Technology, 81, 33-44.

45. Rabelo, S., Filho, R., \& Costa, A. (2008). Applied Biochemistry and Biotechnology, 144, 87-100.

46. Larsson, S., Palmqvist, E., Hahn-Hagerdal, B., Tengborg, C., Stenberg, K., Zacchi, G., et al. (1999). Enzyme and Microbial Technology, 24, 151-159.

47. Mes-Hartree, M., \& Saddler, J. N. (1983). Biotechnology Letters, 5, 531-536. 